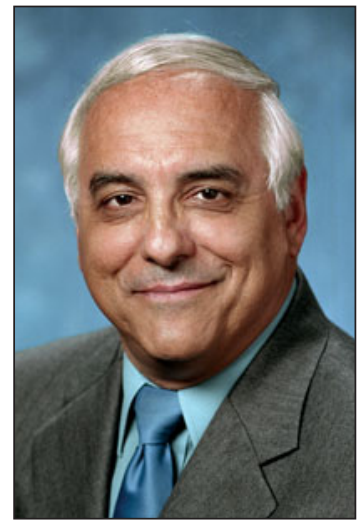

The tremendous growth and success of our Society is the result of member input and the energetic efforts of many MRS volunteers.

\section{Congratulations to the Materials Research Society on its 40th anniversary!}

www.mrs.org/timeline

Orlando Auciello

2013 MRS President

In 1973, our pioneering founders could never have imagined the tremendous growth the Society would see over the next four decades. An initial roster of 215 members swelled to a diverse community of over 16,500 women and men spanning 82 countries. A one-symposium event on phase transitions grew into the MRS Spring and Fall Meetings-interdisciplinary in nature and annually hosting over 11,000 presentations across 100 topical symposia. A slim newsletter known as MRS Bulletin became a precursor to an electronic publications portfolio attracting over 5.8 million abstract views per year. And a lobby display on materials science became Strange Matter, a multinational, multicontinent traveling science museum exhibit.

Of course, the tremendous growth and success of our Society is the result of member input and the energetic efforts of many MRS volunteers. They offer their precious time, their spirit, their expertise, and their unique perspectives for the betterment of the materials community worldwide. We would be remiss if, at this time, we did not thank all those - members, volunteers, officers, headquarters staff, vendors, advertisers, exhibitors, sponsors, host cities, and the materials community — who have helped create the framework upon which the Society has matured and flourished.

Taking this momentum forward, the next 40 years promise to deliver even more excitement and innovation. The Materials Research Society Foundation, launched in 2012, will expand support with permanent funding for grassroots projects that further the MRS mission of advancing materials and improving the quality of life. In just this first year, we've funded three grassroots, member-proposed outreach projects to bring the excitement of scientific literacy and awareness to underrepresented minority students and teachers. In addition, the Foundation funded six University Chapter Special Projects and will increase that support beginning in the new year.

We're also excited that our University Chapter Program is expanding internationally. This allows our talented and enthusiastic students to network and collaborate on ideas 
